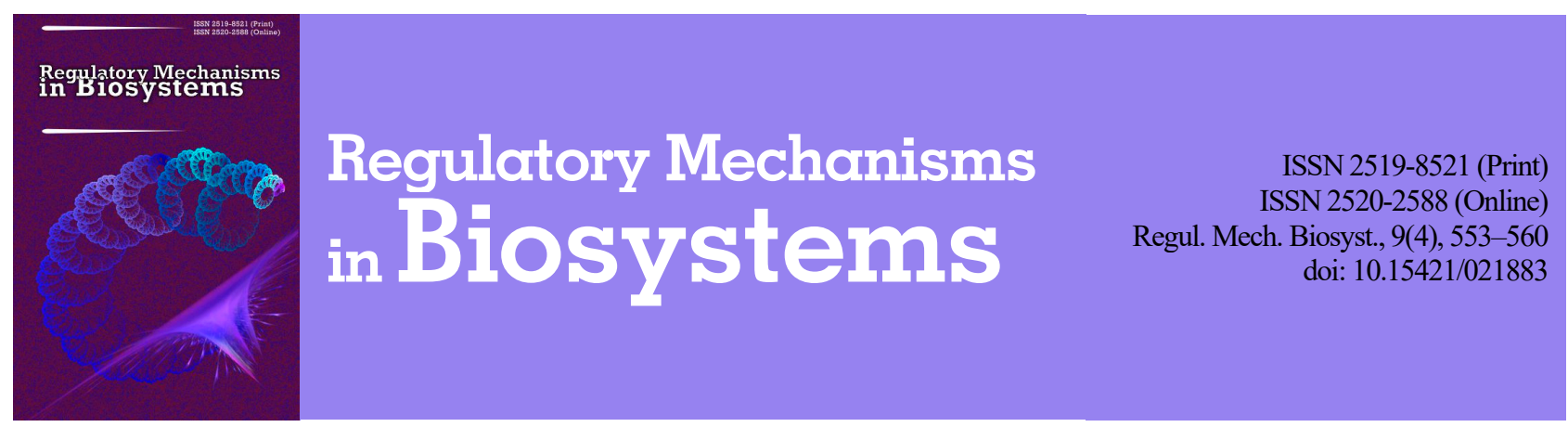

\title{
Modern concept of biological identification of selenoproteins
}

\author{
N. V. Stanishevska \\ SE “Dnipropetrovsk Medical Academy of the Public Health Ministry of Ukraine”, Dnipro, Ukraine
}

Article info

Received 21.09.2018

Received in revised form 17.10.2018

Accepted 19.10.2018

SE "Dnipropetrovsk Medical Academy of the Public Health Ministry of Ukraine",

Sevastopolska st., 19, Dnipro, 49000, Ukraine.

Tel.: +38-067-282-04-05.

E-mail:

natstanishevska3536@gmail.com

\section{Stanishevska, N. V. (2018). Modern concept of biological identification of selenoproteins. Regulatory Mechanisms in Biosystems, 9(4), 553-560. doi:10.15421/021883}

Humans possess 25 selenoproteins, approximately half of which are enzymes (selenoenzymes) required for preventing, regulating, or reversing oxidative damage, while others participate in providing calcium metabolism, thyroid hormone maintenance, protein synthesis, cytoskeletal structure etc. This review examines the latest evidences of the biological effects of selenoproteins according to the method of complex analysis of the material. Selenoprotein P promotes insulin resistance in type 2 diabetes, mediates myocardial ischemic-reperfusion injuries and provides protection against disease by reducing chronic oxidative stress. Selenoprotein $\mathrm{T}$ is expressed at the endoplasmic reticulum membrane in all cells during development, but is confined to endocrine tissues in adulthood, controls homeostasis of glucose and prevents neurodegeneration by reducing oxidative stress factors. Expression of selenoprotein $\mathrm{K}$ is required for efficient $\mathrm{Ca}^{2+}$ flux into melanoma cancer cells, tumour growth and metastasic potential depend on SelK but it suppresses human choriocarcinoma cells. SelK also serves to maintain the normal physiological functions of skeletal muscle. Selenoprotein N deficiency, caused by mutations in the human gene, promotes myopathy characterized by muscle weakness, spinal rigidity, respiratory insufficiency. Sel N participates in normal physiology of skeletal and smooth muscle tissues. Selenoprotein M is located in the endoplasmic reticulum, characterized by high expression in the brain, antioxidative, neuroprotective activity and regulates intracellular $\mathrm{Ca}^{2+}$ levels. Also, the overexpression of SelM was detected in human hepatocellular carcinoma. Selenoprotein $\mathrm{S}$ is mentioned as a regulator of ER stress and inflammatory processes. Selenoprotein $\mathrm{F}$ controls cell proliferation by the impact on Glperiod of the cell cycle. Moreover, it is implicated in the pathogenesis of some types of cancer. The Sel F deficiency reduces the migration and invasive ability of the cells. Knockdown of selenoprotein $\mathrm{W}$ in rodents leads to increased release of $\mathrm{Ca}^{2+}$, causes oxidative ultramicroscopic injuries of the endoplasmic reticulum and mitochondria ultrastructure, which in turn increases the levels of inflammatory factors. Selenoprotein $\mathrm{H}$ is involved in redox regulation, in tumourogenesis. Knockdown of selenoprotein $\mathrm{H}$ decreases cellular differentiation and increases proliferation and migration of cells. Selenoproteins U, V, I, O, R are recently identified and their functions are not clearly known. The data analyzed in the review help determine promising directions in the study of the selenoproteins.

Keywords: selenium; expression of selenoproteins; functions of selenoproteins; antioxidants; deficiency of selenoproteins

\section{Introduction}

Implementation of the influence of the microelement selenium on biological systems is mediated by the inclusion of this element to the aminoacid residue of selenocysteine, which is an integral part of all selenoproteins. About 25 types of selenoproteins are known today, most of them are regulators of oxidative processes (Addinsall et al., 2018) and redox homeostasis (Wrobel et al., 2016). High metabolic activity of selenoproteins, their participation in the pathogenetic links of processes such as oxidative stress (Zachara, 2015; Kim et al., 2017), carcinogenesis (Guerriero et al., 2014; Short \& Williams, 2017; Bertz et al., 2018), neurodegeneration (Pitts et al., 2014; Burk et al., 2014; Boukhzar et al., 2016), insulin resistance (Prevost et al., 2013; Mita et al., 2017), myopathy (Moghadaszadeh et al., 2013), and others underscores the constant interest of the scientific community in the issues of the disclosure of mechanisms for the realization all biological functions of these compounds. (Brigelius-Flohé, 2015). In addition to the generally known glutathione peroxidase, which performs the catalytic function in the reduction of hydroperoxides and lipoperoxids, other selenoproteins have been partially investigated. Thioredoxin reductase is one of them, it exists in three forms TrxR1, TrxR2, TGR (cytosolic, mitochondrial, and in the testicles, respectively). The thioredoxin system is extremely important for mammals, as evidenced by the early embryonic mortality of mice that lacked any of the isoforms (Bobba et al., 2014). Another enzyme inclu- ding selenocysteine residue, iodothyronine deiodinase, plays an important role in the activation and inactivation of thyroid hormones (Hernandez \& Stohn, 2018). Selenophosphate synthetase is a mammalian selenium enzyme that provides a synthesis of other selenogenic enzymes (Na et al., 2018; Tobe \& Mihara, 2018). Methionine-R-sulfoxide reductase participates in protection against oxidative stress (Gladyshev, 2014; Kim et al., 2014). There is a genetic nomenclature of selenoproteins. By the last nomenclature, all proteins that include selenocysteine are divided into proteins with a known function. These are thioredoxin reductase 1 , thioredoxin reductase 2, and thioredoxin reductase 3; glutathione peroxidase 1 , glutathione peroxidase 2 , glutathione peroxidase 3 , glutathione peroxidase 4 and glutathione peroxidase 6 ; iodothyronin deiodinase 1 , iodothyronin deiodinase 2 and iodothyronin deiodinase 3 ; methionine sulfoxide reductase B1, and selenophosphate synthetase 2. Designation of selenoproteins with unknown and unexplored functions by the proposed nomenclature have the following abbreviations; SELENOF (selenoprotein F, 15-kD selenoprotein, SEP15), SELENOH (selenoprotein H, SELH, C11orf31), SELENOI (selenoprotein I, SELI, EPT1), SELENOK (selenoprotein K, SELK), SELENOM (selenoprotein M), SELENON (selenoprotein N, SEPN1, SELN), SELENOO (selenoprotein O, SELO), SELENOP (selenoprotein P, SeP, SEPP1, SELP), SELENOS (selenoprotein S, SELS, SEPS1, VIMP), SELENOT (selenoprotein T, SELT), SELENOV (selenoprotein V, SELV), and SELENOW (selenoprotein W, SELW, SEPW1). This system was agreed upon by the HUGO Genes 
Commodity Committee (Gladyshev et al., 2016). This article is an attempt to systematize the general information of biological effects and the role of newly identified selenoproteins with unexplored functions in pathophysiological and biochemical processes. The data, published in recent years, were analyzed. The main task of the work is to find out promising directions in the issue of authentication of selenoproteins, which in turn will help determine the vectors of subsequent studies of this group of proteins.

\section{General characteristics of selenoproteins}

Trace element selenium (Se) is part of the polypeptide chain of 21 natural amino acids selenocysteine (Sec), which encoded UGA codon. Inclusion Sec in any protein defines the affinity of the last one to selenoproteins. Selenoproteins have definite functions, and their synthesis is dependent on the specific co-factors and dietary Se. It is known that many pathological conditions are associated with changes in the elaboration of selenoproteins and their activity. Emerging evidence points out that selenium deficiency or mutation and polymorphism in genes of selenoproteins is part of the pathogenesis of many diseases, including cardiovascular disorders, immune dysfunction, cancer, muscular and skeletal defects, endocrine dysfunction and neurological maladies (Zoidis et al., 2018).

Selenoproteins with unknown and unexplored functions can be divided into groups according to:

Localization:

- located in the endoplasmic reticulum membrane (Sel N, SelK, SelT);

- located in the endoplasmic reticulum lumen (SelF, SelS, SelM, Sell);

- located in the nucleus (SelH, SelR or methionine-R-sulfoxydructuse 1);

- located in the cytoplasm (SelP, SelW, SelR, SelI);

- location is unknown (SelO, SelU, SelV, Fig. 1).

Biofunctional role:

- regulators of oxidative stress;

- mediators of carcinogenesis;

- providers of insulin resistance and glucose tolerance;

- coordinators of redox homeostasis;

- contractors of neurodegeneration;

- contractors of myopathy.

\section{Selenoproteins of the endoplasmic reticulum membrane}

Selenoprotein T (SELENOT). Selenoprotein T (SelT) belongs to the thioredoxin group of selenoproteins and is regulated by a neuropeptide pituitary polypeptide. Almost every tissue highly expresses SelT during rat embryogenesis. Subsequently, its levels gradually decrease during maturation and adult tissues lose this selenoprotein. In the brain, SelT is highly produced in neuroblasts in different areas, but not determined in mature neurons, except rostral migratory streams of astrocytes and Bergman cells. At the same time, some endocrine tissues continue the expression of SelT throughout life. Among them are: the pituitary gland, the thyroid gland or the testis. SelT expression is detected in chromophilic cells of the pars distalis of the pituitary gland, but in the testis it was observed in spermatogenic cells and Leydig cells only. Additionally, partial hepatectomy exerts SelT expression in liver cells during regeneration. Consequently, it can be concluded that embryogenesis, maturing and regeneration is characterized by SelT induction (Tanguy et al., 2011).

Finding high levels of SelT in pancreatic tissue prompted some researchers to study this selenoprotein in $\beta$-cell-knockout on gene SelT. Glucose administration shows the violation of tolerance to it in mutant animals and insufficiency of insulin production. Morphometric studies show the quantity of Langerhans islands increases while their size reduces. All the above suggests that SelT is localized in the $\beta$ - and $\delta$-cells of the pancreas and is involved in glucose homeostasis (Prevost et al., 2013).

Immunofluorescence and immunogold transmission electron microscopy methods revealed that SelT is produced by all endocrine cells of the pituitary gland. The SelT blockade in corticotropic cells encourages the development of endoplasmic reticulum (ER) stress and reduces the production of hormones. The study identified SelT as a subunit of the protein oligosaccharide transferase complex, which is indispensable for the ER integrity and homeostasis and promotes endocrine cells ripening and their hormone secretion (Hamieh et al., 2017).

On the model of dopaminergic neuron cells, both silencing and excessive SelT expression affects oxidative stress and cell survival. Treatment with Parkinson-inducing neurotoxins , such as 1-methyl-4-phenyl1,2,3,6-tetrahydropyridine (MPTP) or rotenone, causes SelT expression in the nigrostriatal pathway of wild-type mice, promoting rapid and heavy Parkinson-like and motor defects in SelT-deficient mice. This movement deterioration is associated with severe oxidative stress and neurodegeneration, as well as a decrease in the activity of tyrosine hydroxylase and the level of dopamine in the nigrostriatal system (Boukhzar et al., 2016).

Selenoprotein K (SELENOK). Today it is known that selenoprotein $\mathrm{K}$ is located in the ER and maintains a normal physiological state of skeletal muscle. Research has shown that Se deficiency reduces the expression of selenoprotein $\mathrm{K}$ and causes oxidative stress, ER stress, and apoptosis in chicken muscles (Fan et al., 2018).

The development of melanoma, according to research, requires the expression of selenoprotein $\mathrm{K}$, which is necessary for the $\mathrm{Ca}^{2+}$ flux into the cancerous cells. Malignant cells show a strong dependence on the flow of calcium. In one experiment, CRISPR/Cas9 was used to form the selenoprotein $\mathrm{K}$ deficiency in human melanoma cells. This led to a decrease in the $\mathrm{Ca}^{2+}$ flux and impaired function of the specialized receptor (IP3R), which inhibited proliferation, invasion, and cell migration. Consequently, the growth and metastatic potential of the tumours depend on the selenoprotein K synthesis in the cancer cells (Marciel et al., 2018).

According to other data, selenoprotein $\mathrm{K}$ can act as a tumour suppressor in human choriocarcinoma cells, negatively regulating the expression of the beta-subunit of human chorionic gonadotrophin by signaling pathways ERK, p38 MAPK and Akt. All the above suggests that selenoprotein $\mathrm{K}$ may become a new target for human choriocarcinoma in vitro (Li et al., 2018).

Selenoprotein $\mathrm{K}(\mathrm{SelK})$ is a membrane protein that provides antioxidant protection, calcium regulation in the cell. It is a part of the protein degradation pathogenetic link related with the ER. The activity of low-speed peroxidase is regulated by SelK but within the range of other peroxidases. In particular, SelK reduces hydrophobic substrates, such as phospholipid hydroperoxides, thereby preserving membrane integrity. Hence, SelK can take part in membrane reconstruction. Diselenide bond, as SelK demonstrated, is the first linkage in the molecule, which is reported for selenoprotein. The redox potential of SelK was much higher potential $(-257 \mathrm{mV})$ than that of diselenide bonds in small molecules or proteins. So, SelK can be reduced by thioredoxin reductase. These findings are important for identification of SelK (Liu et al., 2014).

Selenoprotein N (SELENON). SelN gene damage causes the myopathy associated with this gene, characterized by muscle weakness, spinal rigidity, and respiratory insufficiency. In Sel N-knockout mice under normal conditions, the histology of the muscles remains normal, but in skeletal muscle, after detecting oxidative stress, significant fine damage can occur. Ryanodine receptor calcium release channels (RyR) reveal a weaker sensibility to caffeine in SelN deficient myofibrils, displaying the possible role of SelN in the RyR regulation. The SelN deficiency also leads to the pathological development of the lungs, which is characterized by expanded alveoli. This is associated with impaired of tissue elasticity and enhancement in quasi-static lung ductility. This conclusion increases the possibility that the respiratory syndrome observed in patients with SEPN1 mutations may have a primary pulmonary component, in addition to the weakness of the respiratory muscles (Moghadaszadeh et al., 2013).

Pathological changes in the SelN gene cause a group of muscle violations. In this case, the axial muscles are affected. Involvement of the SelN in $\mathrm{Ca}^{2+}$ and redox homeostasis was demonstrated in some studies, but how it participates in skeletal muscle physiology remains unclear. To find out the SelN function in vivo, a group of researchers created a model of SelN knockout mice. These mice are characterized by usual parameters of maturing and morphology, they had the appearance of wild mice. Usually, SelN knockout mice display trivial defects only of muscle microstructure and contractile features. Forced training by swimming contributes to the development of specific phenotype ma- 
nifestations characterized by limited mobility and rigidity of the body as well as progressive curvature of the spine and an overwhelming change in the paravertebral muscles in SelN knockout mice. This induced phenotype repeats the disturbances of these muscles in patients with myopathy associated with damage to the SEPN1 gene (Rederstorff et al., 2011).

There are interesting results of studies in which selenoprotein $\mathrm{N}$ (SelN, SEPN1) expression was observed, depending on the deficiency and excess selenium in the diet. It has been shown that SelN expression in the cardiac muscle tissue corresponds to the dietary concentrations of selenium. Expression of the SelN in the heart muscle is suppressed in the case of selenium deficiency while with excessive consumption stimulation of expression is increased compared to moderate selenium use. Also, levels of mRNA were studied. Selenium deficiency did not affect the level of SelN mRNA.

However, SelN mRNA levels showed various expressions in different skeletal and cardiac muscles. Moreover, Se also regulates the levels of SPS1 (Selenoprotein S) and SecS mRNAs. Thus, Se regulates the expression of SelN gene and affects SecS and SPS1 mRNA levels. The consumption of Se in the diet can regulate the SelN biosynthesis by influencing SPS1 and SecS mRNA levels (Zhang et al., 2014).

One study was directed to elucidate the dietary Se impact and mechanism of action on the contraction of uterine smooth muscle using SelN on a mouse model. Quantitative polymerase chain reaction analysis was used to determine the levels of mRNA. Western blotting was performed to detect protein levels. The results of immunohistochemical analysis showed that $\mathrm{Se}$ affects the smooth muscle of the uterus. Addition of selenium increased the release of $\mathrm{Ca}^{2+}, \mathrm{Ca}^{2+}$-calmodulin, myosin lung kinease expression and myosin light chain phosphorylation, but did not affect reactive oxygen species (ROS). Thus Se plays an important role with SelN in regulating smooth muscle contraction of the uterus (Zhou et al., 2018).

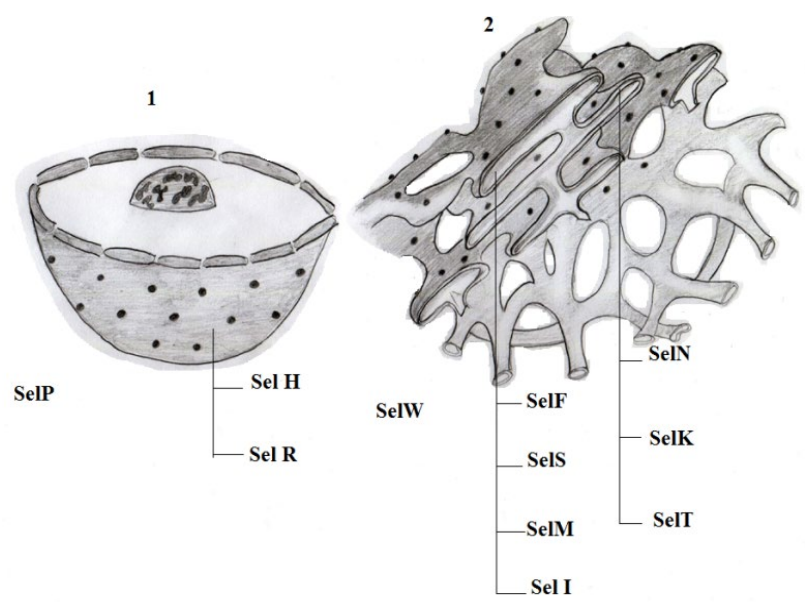

Fig. 1. Localization of selenoproteins: 1 -nucleus, 2 - endoplasmic reticulum, SelN - selenoprotein N, SelK - selenoprotein K, SelT - selenoprotein T, SelF - selenoprotein F, SelS - selenoprotein S, SelM - selenoprotein M, SelI - selenoproten I, SelH - selenoprotein H, SelR - selenoproten R, SelP - selenoprotein P, SelW - selenoprotein W

\section{Selenoproteins of the endoplasmic reticulum lumen}

Selenoprotein M (SELENOM). Recently it was determined that human hepatocellular carcinoma cells reveal excessive SelM expression. SelM expression is associated with an aggravation of malignancy. The authors proposed the use of SELM as a predicted marker for hepatocellular carcinoma (Guerriero et al., 2014).

Earlier, data revealed that selenoprotein $\mathrm{M}$ may function as thiol disulfide oxidoreductase, which is involved in the formation of disulfide bonds, and may be associated with the transport of $\mathrm{Ca}^{2+}$. However, selenocysteine is present in it, and selenoprotein $\mathrm{M}$ can also function as a regulator of oxidative processes, since its decreased or increased expression, regulated by dietary selenium, changes the redox homeostasis (Guariniello et al., 2014). The interaction of some selenoproteins is inte- resting. Thus, selenoprotein $\mathrm{P}$ (SelP-H) and mutant selenoprotein $\mathrm{M}$ (SelM) are able to bind ions of transition metal and modulate $\mathrm{Zn}^{2+}$ mediated amyloid- $\beta(\mathrm{A} \beta)$ aggregation, production of ROS and neurotoxicity. Aggregation and cytotoxicity of amyloid- $\beta(A \beta)$ peptide with transition metal ions in neuronal cells are engaged in the progression of Alzheimer's disease. The binding of $\mathrm{A} \beta$ to $\mathrm{Zn}^{2+}$ almost completely suppressed the fibrillation of $A \beta$, which could be significantly restored by SelP-H and SelM, which was observed by fluorescence and electron transmissive microscopy. Both SelP-H and SelM inhibit $\mathrm{Zn}^{2+}-\mathrm{A} \beta$-induced neurotoxicity and intracellular synthesis of ROS in living cells. Studies have shown that SelP and SelM can play a greatly role in regulating the oxidation-reducing balance, as well as metallic homeostasis (Du et al., 2013).

Expression of SelM is observed in the genesis of the axial skeleton of chickens and rodents. It was most pronounced in osteoblasts, tendons and bones (Grosch et al., 2013). SelM expression is also fixed in embryonic human kidney cells. Full-size SelM prevents aggregation of $\mathrm{A} \beta$ ( $\beta$-amyloid, an appropriate Alzheimer's disease protease) by counteracting the oxidative stress which occurs in O-oligomer cells (Chen et al., 2013).

Common proteins have been extracted to find out the general changes in the of all kidney proteins of transgenic rodents characterized by excess SelM expression. Synthesis of protein was greatly higher in transgenic rodents than in the control (LAP3, BAIAP2L1, CRP2, CD73, PDGF D, KIAA143, PRPPS-AP2, ZFP313, HSP-60, and N-WASP), while other proteins were diminished (ALKDH3, rMCP-3, STC-1). Selenium administration promoted amplified production levels of the five highly expressed proteins in control mice, while transgenic animals did not undergo changes (Goo et al., 2013).

Changes in global protein synthesis were measured in the cerebral cortex in transgenic rats that expressed SelM and non-transgenic rats.

1) Comparison of transgenic rats with non-transgenic animals revealed high parameters of enzyme activity for antioxidant protein in the cerebral cortex.

2) Rise in activity of these enzymes stimulates depletion of the total antioxidant content and activity of $\gamma$-secreas in transgenic rats.

3) Five proteins were amplified, and three of them were reduced as a result of excessive SelM expression.

4) Among the five upregulated proteins, two of them were enlarged in both groups after addition of selenium, while the eukaryotic factor for initiating $4 \mathrm{H}(\mathrm{eIF}-4 \mathrm{H})$ and lactate dehydrogenase B (LDH-B) increased or decreased under the same conditions.

5) Three downregulated proteins did not cause considerable changes in expression after the administration of selenium (Kim et al., 2014).

Selenoprotein $\mathrm{M}$ is highly produced in the human brain, but the biological effect and molecular mechanism remain obscure. For verification of SelM mechanisms of action, a mutant selenoprotein $M$ was created. Then it was discovered that the new interactive SelM protein is galectin-1 (Gal-1). Gal-1 plays a crucial role in preventing neurodegeneration and promoting neuroprotection in the brain, the interaction between SelM and Gal-1 demonstrates a new direction in the study of the biological function of SelM in the human brain (Qiao et al., 2013).

Se deficiency induces a decrease in the content of glutathione peroxidase and the activity of catalase; elevated levels of malondialdehyde and reduced expression of selenoprotein RNA (mRNA) and an essential reduction in SelM protein in the brain (Huang et al., 2016).

Selenoprotein S (SELENOS). The next selenoprotein related with the ER is selenoprotein S, which, by cooperation with another membrane protein (valozin-containing protein), provides the incorporation of selenoprotein $\mathrm{K}$ into the ER. The main evidence of this is that interaction between selenoprotein $\mathrm{K}$ and valozin-containing protein does not occur in cells deprived of selenoprotein $\mathrm{S}$, while selenoprotein $\mathrm{S}$ interacts with valozin-containing protein, regardless of the presence or absence of selenoprotein $\mathrm{K}$. Expression of selenoprotein $\mathrm{S}$ and $\mathrm{K}$ rises according to stress of the ER (Lee et al., 2015).

The expression and location of SelS, its function and regulatory factors in the intact and inflammatory intestine epithelium have been defined. SelS was elevated in inflamed ileal tissues in patients with Crohn's disease. The same elevation was observed in mice models of enterocolitis. SelS expression was not connected with the differentiation 
of enterocytes, but increased in response to the supplementation of selenium and after correction of ER stress by an inducer of tunicamycin. Therefore SelS can be considered as a new marker for endoplasmic reticulum intestinal stress (Speckmann et al., 2014).

To study the role of SelS in the adjustment of ER stress, the interaction of selenoprotein with the membrane protein p97 on mouse neuroblastoma cells and human embryonic kidney cells were explored. SelS expression level was always enhanced when there was an ER induction of stress (Lee et al., 2014).

Selenoprotein S (SelS), as one of the coordinators of the inflammatory process, responds to ischemia. Recently, the exploration of transitory cerebral ischemia aftermaths was conducted. A decline in SelS synthesis in the ischemic cell was observed 3-7 days after occlusion, but in the zones adjacent to hypoxic site there was an elevation in SelS expression corresponding to reactive astrogliosis (Liu et al., 2013).

Cell culture has shown that SelS overexpression mitigates cytotoxicity and apoptosis induced by ochratoxin, as well as increases glutathione levels and reduces ROS, overwhelms ochratoxin-induced phosphorylation. Conversely, the SelS knockdown reduces glutathione levels, enhances the generation of ROS and ochratoxin-induced phosphorylation to the same extent as cytotoxicity and apoptosis (Gan et al., 2017).

Selenoprotein $\mathrm{S}$ is highly expressed in skeletal muscle. The depression of the SelS gene greatly exacerbates the inflammatory profile of fast muscle fibers, which are generally more susceptible to degeneration in dystrophy (Wright et al., 2017).

Enhanced SelS expression increases the level of nitric oxide and endothelial nitric oxide synthase in endothelial cells treated by the tumour necrosis factor (TNF- $\alpha$ ). A study was conducted on the human umbilical vein endothelial cells culture (HUVECs). Moreover, overexpression of SelS keeps out the TNF- $\alpha$-induced adhesion of THP- 1 cells to endothelial cells. Also, SelS overexpression regulates TNF- $\alpha$-induced inflammatory factors, including interleukin- $1 \beta$, interleukin- 6 , interleukinin- 8 , and monocytic chemotaxic protein-1. Conversely, the SelS knockout of siRNA leads to an increased TNF- $\alpha$-induced injury in HUVECs. Thus, SelS protects endothelial cells from TNF- $\alpha$-induced dysfunction (Cui et al., 2018).

Atherosclerotic vascular lesions may be accompanied by calcification and differentiation of osteoblasts. Osteoblast differentiation and calcification, which are induced by lipopolysaccharides (LPS) or TNF- $\alpha$ were significantly aggravated with SelS knockdown in vascular smooth muscle cells. The SelS knockdown also exacerbates the LPS-induced increase in the expression of proinflammatory cytokines TNF- $\alpha$ and interleukin-6, as well as increased expression of stress markers of ER. Thus, it can be assumed that SelS can suppress inflammation-induced calcification of smooth myocytes in vessels due to suppression of signaling pathways of nuclear factors and endoplasmic reticulum stress (Ye et al., 2018).

Selenoprotein F (SELENOF). The selenoprotein F or $15 \mathrm{kDa}$ is localized in the lumen of the ER and takes part in quality controlling of protein compaction. The RNA-induced deficiency of Sel F leads to inhibition of cell proliferation, whereas cell growth is restored after removal of the knockdown inductor. SelF deficient cells are blocked in the G1 phase and show signs of ER stress. In addition, the Sel F deficiency leads to the displacement of the adhesive contacts of the cells to the periphery of the basal part, and also diminishes the migration and cellular invasive power. But all these changes are reversible and depend on the state of Sel F. Thus, it can be noted that Sel F plays a crucial role in adjustment of the G1 cell cycle phase as well as cell mobility (Bang et al., 2015). Selenoprotein F shows the ability to react with an enzyme retinol dehydrogenase that catalyzes the recovery of trans-retinol (vita$\min \mathrm{A}$ ). At the same time there is a blockage of this enzyme. Consequently, the overexpression of selenoprotein $\mathrm{F}$ leads to a decline in the retinol synthesis (Tian et al., 2018).

In the study of ultramicroscopic features in Sel F deficient cells, most of them exhibited the formation of membrane vesicles. Accumulation of bubbles modifies the shape of cells from a flat spindle to a spherical one. In such cells, actin fibrils are displaced to the periphery, overlapping $\alpha$-tubulin. These morphological alterations are invertible, and inhibited by inhibitors of Rho-associated protein kinase. Sel F deficient cells are nonapoptotic and show a clear localization of F-actin and $\alpha$-tubulin, as opposed to typical apoptotic blebbing cells. Thus, it can be argued that Sel F regulates the pathway that counteracts the RhoA / ROCK / MLC-dependent non-apoptotic bubble formation (Bang et al., 2015).

\section{Nuclear selenoproteins}

Selenoprotein H (SELENOH). Selenoprotein H is a newly identified selenoprotein, which is a nucleolar oxidoreductase. According to some authors, SelH regulates redox homeostasis and suppresses DNA damage (Cox et al., 2016). Selenoprotein $\mathrm{H}$ defends cells from aging through the effect on oxidative stress by supporting the genome $\mathrm{Wu}$ et al., 2014). Human cells, in which the SelH expression was generated, were exposed to glutamate, which is known for its pathogenicity and its ability to cause cell death mediated by mitochondrial damage. The results of the study showed that cytotoxicity of glutamate is bound to an increase in the production of ROS, an imbalance in the dynamics of mitochondria and autophagy. These changes disappeared, and cellular integrity was restored by excessive SelH expression (Ma et al., 2017).

It is believed that SelH is involved in redox homeostasis, as well as teratogenesis. Expression of SelH is elevated in tumour tissue, in undifferentiated epithelial cells of the gastrointestinal tract of mice. The suppression of Sel H expression by knockdown reduces cell differentiation and enhances proliferation and migration. Moreover, SelH knockdown cells are more capable of creating tumour colonies and xenografts. However, they show a more accelerated cell cycle. The foregoing indicates $\mathrm{SelH}$ is the leading regulator of cell cycle progression and prevents uncontrolled proliferation. SelH expression is consistently dependent on Se, so the effect of selenium addition on cancer initiation and progression is probably due to SelH (Bertz et al., 2018).

Selenoprotein R (SELENOR). Selenoprotein R (SelR), known as methionine sulfoxydreductase, is an enzyme whose role was studied in the SelR-knockdown epithelial cells of the eye lens, against the background of galactose-induced apoptosis. The results have shown both d-galactose and the SelR-gene knockdown independently induce oxidative stress. But the effect of galactose on cells under the SelR knockdown induces an even greater elevation in glucose-regulated protein levels, and lowers mitochondrial membrane potential, which is accompanied by the liberation of mitochondrial cytochrome. At the same time, the percentage of cells with apoptosis significantly increases. Thus, SelR can protect the mitochondria of lens epithelial cells against oxidative stress, and weaken apoptosis in these cells (Dai et al., 2016).

The antioxidant properties of SelR are elucidated in a number of studies. Thus, SelR-deficient mice exhibit significantly greater sensitivity to acetaminophen-induced hepatocyte damage than mice without deficiency. This is confirmed by necrotic lesions in the central areas of the liver lobes, as well as laboratory data (Kim et al., 2017; Singh et al., 2017).

Similar changes were observed in the kidney model. The SelR knockdown in mouse kidney cells causes increase in cisplatin-induced lesions. Cisplatin induces swelling, loss of cristae and fragmentation of mitochondria with an increase in peroxide lipid edema, especially in SelR-deficient kidneys compared to kidneys with normal SelR expression (Noh et al., 2017).

MsrB1 (or SelR) is highly expressed in immunoreactive macrophages and contributes to the realization of cellular and organismal immune responses. MsrB1 controls immune responses by facilitating the detection of anti-inflammatory cytokines in macrophages. MsrB1 dependent reduction of oxidized methionine in proteins may constitute an unrecognized regulatory mechanism underlying immunity and inflammatory disease, and a new target for clinical applications (Lee et al., 2017).

Decreased expression of MsrB3 (methionine sulfoxide reductase B3) promote apoptosis of cancer cells by the mitochondrial pathway and leads to the undoing of cancer cells. The deficiency of MsrB3 greatly increased the ER stress, which led to apoptosis. In addition, depletion of MsrB3 activates the proapoptotic Bim molecule, which is essential for ER-stressed apoptosis. The deficiency of MsrB3 increases the level of cytosolic calcium, suggesting that overexpression of MsrB3 leads to violations of calcium homeostasis in $\mathrm{ER}$, which, as a result, causes endoplasmic reticulum stress. MsrB3 plays a decisive role in cancer cell apo- 
ptosis due to modulation of the stress state of ER (Kwak \& Kim, 2017). SelR can directly interact with $A \beta 42$ (amyloid- $\beta$, a central protein in Alzheimer's disease), and the interaction between SelR and A $\beta 42$ is confirmed by fluorescence resonance energy transfer and co-immunoprecipitation. SelR is closely related to Alzheimer's disease (Wang et al., 2017).

\section{Cytoplasmic selenoproteins}

Selenoprotein P (SELENOP). According to published data, circulatory selenoprotein $\mathrm{P}(\mathrm{SePP})$ is linked to bone metabolism, but its function for bone balance is not completely known. Some researchers report that selenoprotein $\mathrm{R}$ is an important transporter of $\mathrm{Se}$ to the bones. Se is necessary for normal osteogenesis, which is confirmed by the data on Kashin-Beck disease, endemic Se-dependent osteoarthritis (Pietschmann et al., 2014).

One study examined the role of selenoprotein P (SelP) in recirculatory and ischemic alterations. The study was conducted in SelP-knockout mice group and in wild mice. Both groups were exposed to 30-minute ischemia, followed by 24-hour reperfusion. The area of myocardial infarction, which was evaluated by Evans coloration, was significantly less in the SelP-knockout mice group than in the wild mice. There was also a significant increase in the size of the heart in mice that excessively expressed SelP in the liver compared to other mice in the modeling of ischemia-reperfusion. These data indicate that SelP inhibition protects the heart against damage from ischemia-reperfusion (Chadani et al., 2018).

Glucose administration increases the expression of genes and the transcriptional activity of SelP in cultured hepatocytes. Physiological SelP concentrations inhibit cell proliferation stimulated by vascular endothelial growth factor (VEGF), tubular formation and migration in the endothelium of the human umbilical vein. SelP inhibits the generation and phosphorylation of VEGF-induced reactive oxygen species and extracellular signaling regulated kinase in the endothelium of the human umbilical vein. Healing of the wound is disturbed in SelP expressing mice, while healing in SelP-knockout mice was improved (Ishikura et al., 2014).

According to some researchers, selenoprotein P (SelP), a liver secretory protein, causes resistance to insulin. Using sequential gene expression analysis (SAGE) and DNA chip methods, it was found that levels of SelP mRNA correlate with insulin resistance in humans. The introduction of purified SelP disrupts insulin signaling and regulates glucose metabolism in both hepatocytes and myocytes. Conversely, both knockout and interference mediated elimination of SelP RNA improved system sensitivity to insulin and glucose tolerance in mice. SelP's metabolic action is mediated, at least in part, by inactivation of adenosine monophosphate-activated protein kinase (AMPK). Thus, these results demonstrate the role SelP plays in the regulation of glucose metabolism and insulin sensitivity, suggesting that SelP may be a therapeutic target for type 2 diabetes (Misu et al., 2010).

Distinct clinical investigations have proved the linkage of selenoprotein $\mathrm{P}$ and insulin resistance. The researches compared serum SelP content of one hundred persons with different glucose insensitivity states. In addition, of some cardiac metabolic risk factors with SelP were evaluated. Among them were the intima-media thickness of the carotid artery, insulin resistance and high sensitivity of the C-reactive protein. In the serum of type 2 diabetes persons and prediabetes patients, concentration of SelP is significantly higher, and it is lower in patients with normal glucose tolerance and gradually decreasing. The same differences of SelP in blood were observed in patients with overweight and normal weight, respectively. Strong correlation was detected by Spearman's partial correlation analysis between serum SelP and most risk factors such as insulin resistance, body mass index, systolic blood pressure, hemoglobin, glucose, aspartate aminotransferases, triglycerides, waist circumference. Consequently, glucose tolerant persons serum SelP parameters were increased and related to some cardiac metabolic factors such as atherosclerosis, insulin resistance, and inflammation (Yang et al., 2011).

Selenoprotein P (SelP) is defined as hepatokin and promotes type 2 diabetes insulin resistance. The depression of SelP activity may improve glucose metabolism. The monoclonal antibody AE2 with neutralizing activity against SelP was elaborated, administration of which to mice significantly improved glucose intolerance and insulin resistance. Moreover, the excessive administration of SelP significantly reduces the level of insulin in the pancreas and glucose-induced insulin secretion, which improves when AE2 is administered. The mapping of the epitope shows that $\mathrm{AE} 2$ recognizes the SelP region of a person adjacent to the first histidine-rich area. The anti-SelP polyclonal antibody improved glucose intolerance and insulin secretion in the diabetes model (Mita et al., 2017).

SelP-deficient mice exhibit a "super-sustainability" phenotype after training, as well as enhanced production of ROS, phosphorylation of protein kinase and activation of the proliferative receptor with peroxide. However, the addition of $\mathrm{N}$-acetylcysteine antioxidant reduces the production of ROS and endurance in SelP deficient mice (Misu et al., 2017).

There are data about the interaction of SelP with tubulin in human embryonic brain cells, as evidenced by the analysis of fluorescence resonance energy transfer (FRET) and co-immunoprecipitation reactions (Du et al., 2014).

Selenoprotein W (SELENOW). The study of selenoprotein W, in most cases, was performed on the model of chickens. So, it is wellknown that excess $\mathrm{Ca}^{2+}$ is present in Se deficiency, but the mechanisms of this phenomenon are not sufficiently studied. That is why this process was studied in the sample of chicken embryo and SelW knockdown myoblasts. It was found that Se deficiency induces typical muscle damage that is accompanied by a $\mathrm{Ca}^{2+}$ disorder, oxidative stress, which damages the ultrastructure of the sarcoplasmic reticulum and mitochondria; reduction of $\mathrm{Ca}^{2+}$ channels, decrease of levels of seleniumcontaining enzymes SERCA, SLC8A, CACNA1S, ORAI1, STIM1, TRPC1, and TRPC3. Similar changes are also observed in the case of modeling of SelW knockout myoblasts (Yao et al., 2016).

Also the effect of selenoprotein $\mathrm{W}$ on lymphoid tissues and cultivated spleen leukocytes was studied in the inflammatory process of chickens. The use of the selenogenic deficiency diet effectively reduces the expression of SelW mRNA and induces a considerable increase in parameters of COX-2 (cyclooxygenase-2), iNOS (nitric oxide synthase), $\mathrm{NF}-\mathrm{kB}$ (nuclear factor kB), PTGE and TNF- $\alpha$ (tumour necrosis factor). Histological analysis also indicates lymphoid tissue damage in incident of selenium deficiency. There is an increase in the mRNA parameters of inflammatory factors in lymphocytes pretreated with $\mathrm{H}_{2} \mathrm{O}_{2}$, which is not registed when the culture of lymphocytes before $\mathrm{H}_{2} \mathrm{O}_{2}$ is treated with $\mathrm{Se}$. Thus, the SelW inhibition leads to stimulation of the inflammatory factors genes in cultured lymphocytes of the spleen (Yu et al., 2015).

Earlier, the effect of SelW gene blocking on viability and cell apoptosis, SelW mRNA expression levels when treated with $\mathrm{H}_{2} \mathrm{O}_{2}$ were studied on the pulmonary lymphocytes. The study outcomes indicated that cell treatment with sodium selenite vastly elevates SelW expression, and $\mathrm{H}_{2} \mathrm{O}_{2}$-induced cell apoptosis was significantly reduced, cell viability was also increased. Elimination of the SelW lymphocyte gene reduces cell viability, accelerates apoptosis and increases sensitivity to $\mathrm{H}_{2} \mathrm{O}_{2}$ (Yu et al., 2014).

One study tested the ability of various selenium combinations, such as sodium selenite, methylseleninic acid, methyl selenocysteine, selenomethionine, to increase the activity of proteins or mRNAs that are typical of selenium status biomarkers, namely glutathione peroxidase, thioredoxin reductase, selenoprotein $\mathrm{W}$, selenoprotein $\mathrm{H}$ and selenoprotein F on models of various cell lines. The most effective in increasing all biomarkers were selenite sodium and methyl selenium cholesterol, while other compounds had only minor effects (Kipp et al., 2013).

Selenoproteins with the least studied functions: V (SELENOV), I (SELENOI), U (SELENOU), O (SELENOO). The recently discovered selenoprotein $U$ is characterized by considerable autophagosome formation and lysosome degradation with intact cytoskeleton in Sertoli cells that are exhausted or deprived of this protein. These data indicate that the deposition of selenoprotein $U$ causes autophagy and reduces the expression of important growth factors in Sertoli cells by way of signaling pathway disturbances. Generally, selenoprotein $U$ is important for the survival and functioning of the Sertoli cells (Sattar et al., 2018).

The functions of most selenoproteins are not yet identified. Among these, there is also selenoprotein V. SelV expression reaches its secretory peak during puberty, while progressive decline of expression is revealed in adult mice. SelV also has activity of glutathione peroxidase and thio- 
redoxin reductase (Varlamova et al., 2015). SelV (Selenoprotein V) has a thioredoxin-like folding and a conservative motif (CXXU, where $\mathrm{C}$ is cysteine, U-selenocysteine) in its catalytic center; it belongs to the fraction of redox proteins whose participants are engaged in oxidative-reduction reactions. The SelV redox protein can interact with the O-linked $\mathrm{N}$-acetylglucosamine transferease (OGT) and proteins belonging to the ASB family: Asb-17 and Asb-9. Specificity of SelV interactions with OGT and Asb-9, but not with Asb-17, is confirmed by immunoprecipitate. Additionally, SelV mRNA expression has been shown in later stages of spermatogenesis, as well as during puberty and reproduction of rats (Varlamova et al., 2012).

The function of SelO has not been clarified, however, there are reports of the effects of SelO on chondrocyte differentiation, notably the increase of the mRNA levels and SelO expression when chondrogenic induction of ATDC5 cells. The silencing of the SelO gene leads to inhibition of chondrogenic differentiation, which is accompanied by the accumulation of several cartilaginous glycosaminoglycans and decreased activity of alkaline phosphatase in selenium deficiency cells. The inhibition of proliferation is also due to delay in the progression of the cell cycle. The deficiency of SelO stimulates the extinction of chondrocytes by apoptosis (Yan et al., 2016).

The intracellular localization of SelI human selenoprotein and the levels of gene expression in various human tumour cell lines are determined. SelI protein was found in the nucleus, cytoplasm and endoplasmic reticulum, and absent in the nucleolus (Varlamova et al., 2017). For the convenience of perception, all the information is provided in Table 1 .

Table 1

The general characteristic of selenoproteins (the analysis is based on publications over the last 5 years)

\begin{tabular}{|c|c|c|c|}
\hline Name of selenoprotein & Localization & Biological effects & $\begin{array}{l}\text { Knockdown effects on the corresponding } \\
\text { gene (exclusion of the gene) }\end{array}$ \\
\hline SELENOF & $\begin{array}{l}\text { Lumen of } \\
\text { endoplasmic } \\
\text { reticulum }\end{array}$ & $\begin{array}{l}\text { Quality control of protein compaction regulates the G1 period of } \\
\text { the cell cycle, as well as cellular mobility. It inhibits retinol } \\
\text { dehydrogenase, which reduces the production of retinol }\end{array}$ & $\begin{array}{l}\text { It inhibits cell proliferation, causes cells blockade in the G1 } \\
\text { period, endopasmic reticulum stress, displacement of cells } \\
\text { adhesive contacts, accumulation of membrane nonapoptotic } \\
\text { vesicles }\end{array}$ \\
\hline $\begin{array}{l}\text { SELENOH } \\
\text { (nuclear oxide reductase) }\end{array}$ & Nucleus & $\begin{array}{l}\text { Involved in redox regulation, teratogenesis (elevated in tumours), } \\
\text { regulator of cell cycle progression, prevents uncontrolled } \\
\text { proliferation. With excessive expression, it exhibits antioxidant } \\
\text { properties. Protects DNA from damage }\end{array}$ & $\begin{array}{l}\text { Reduces cell differentiation and increase proliferation and } \\
\text { migration }\end{array}$ \\
\hline SELENOI & $\begin{array}{l}\text { Cytoplasm, nucleus, } \\
\text { endoplasmic reticulum }\end{array}$ & Expressed in tumours of different human cell lines & Unknown \\
\hline SELENOK & $\begin{array}{l}\text { Endoplasmic } \\
\text { reticulum membrane }\end{array}$ & $\begin{array}{l}\text { Regulates } \mathrm{Ca}^{2+} \text { flux in cancer cells, provides antioxidant } \\
\text { protection, calcium regulation in the cells, and the pathway for } \\
\text { degradation of the protein associated with the endoplasmic } \\
\text { reticulum. Affects the physiological state of the muscles. } \\
\text { Reduces phospholipid hydroperoxides (antioxidant function) }\end{array}$ & $\begin{array}{l}\text { Provides reduction of } \mathrm{Ca}^{2+} \text { in cancer cells and impaired } \\
\text { function of the specialized receptor (IP3R), which inhibits } \\
\text { proliferation, invasion and cell migration }\end{array}$ \\
\hline SELENOM & $\begin{array}{l}\text { Lumen of } \\
\text { endoplasmic } \\
\text { reticulum }\end{array}$ & $\begin{array}{l}\text { Involved in teratogenesis (increased expression in liver tumours). } \\
\text { Transportation of } \mathrm{Ca}^{2+} \text { affects redox homeostasis }\end{array}$ & Unknown \\
\hline SELENON & $\begin{array}{l}\text { Endoplasmic } \\
\text { reticulum membrane }\end{array}$ & $\begin{array}{l}\text { Participates in calcium and redox homeostasis, but mechanisms } \\
\text { of regulation of skeletal, cardiac muscles, smooth muscles are } \\
\text { unknown }\end{array}$ & $\begin{array}{l}\text { Demonstrates limitation of mobility and rigidity of the body, } \\
\text { as well as the progressive curvature of the spine and the predo- } \\
\text { minant change in paravertebral muscles (signs of myopathy) }\end{array}$ \\
\hline SELENOO & Unknown & Affects the differentiation of chondrocytes & $\begin{array}{l}\text { Stimulates inhibition of chondrocytes differentiation, } \\
\text { delayed progression of the cell cycle, loss of chondrocytes }\end{array}$ \\
\hline SELENOP & $\begin{array}{l}\text { Cytoplasm, secretion } \\
\text { by hepatocytes }\end{array}$ & $\begin{array}{l}\text { Regulation of glucose metabolism and insulin sensitivity contri- } \\
\text { butes to the development of insulin resistance in type } 2 \text { diabetes }\end{array}$ & $\begin{array}{l}\text { Provides improvement of systemic insulin sensitivity and } \\
\text { glucose tolerance in mice, formation of the "super-sustaina- } \\
\text { bility" phenotype, increasing the production of reactive } \\
\text { oxygen species, reducing the area of myocardial infarction }\end{array}$ \\
\hline $\begin{array}{l}\text { SELENOR (methionine- } \\
\text { R-sulfoxid reductase) }\end{array}$ & Nucleus, cytoplasm & $\begin{array}{l}\text { It can protect mitochondria from oxidative stress, and weaken } \\
\text { apoptosis in cells }\end{array}$ & Induces oxidative stress \\
\hline SELENOS & $\begin{array}{l}\text { Lumen of } \\
\text { endoplasmic } \\
\text { reticulum }\end{array}$ & $\begin{array}{l}\text { Endoplasmic reticulum stress marker, regulator of inflammatory } \\
\text { processes }\end{array}$ & $\begin{array}{l}\text { Reduces the level of glutathione, enhances the production of } \\
\text { reactive oxygen species, aggravates the cytotoxicity and } \\
\text { apoptosis. Exacerbates the inflammatory profile of fast } \\
\text { muscle fibers, differentiation, and calcification of osteoblasts }\end{array}$ \\
\hline SELENOT & $\begin{array}{l}\text { Endoplasmic } \\
\text { reticulum membrane }\end{array}$ & $\begin{array}{l}\text { It is a subunit of the protein oligosaccharide transferase complex. } \\
\text { Provides the regulatory function of the endocrine glands, the } \\
\text { control of glucose homeostasis. It is expressed by cells in the } \\
\text { embryogenesis, during the maturation of tissues, and regeneration }\end{array}$ & $\begin{array}{l}\text { Violation of glucose tolerance, deficiency of insulin } \\
\text { products, rapid and severe Parkinson-like and motor defects }\end{array}$ \\
\hline SELENOU & Unknown & $\begin{array}{l}\text { The least studied. Can regulate the expression of important } \\
\text { growth factors in Sertoli cells }\end{array}$ & $\begin{array}{l}\text { Considerable autophagy and lysosomal degradation with } \\
\text { the intact cytoskeleton in Sertoli cells }\end{array}$ \\
\hline SELENOV & Unknown & $\begin{array}{l}\text { Shows signs of belonging to the system of redox regulation, } \\
\text { taking part in oxidative-reduction reactions. Maximum expres- } \\
\text { sion in animals is found during puberty, in adults is reduced }\end{array}$ & Unknown \\
\hline SELENOW & Cytoplasm & $\begin{array}{l}\text { Regulator } \mathrm{Ca}^{2+} \text { releasing due to the effect on its channels in the } \\
\text { sarcoplasmic reticulum of myosimplast }\end{array}$ & $\begin{array}{l}\mathrm{Ca}^{2+} \text { releasing, typical muscle damage, decreased cell viabi- } \\
\text { lity, accelerated apoptosis and increased sensitivity to } \mathrm{H}_{2} \mathrm{O}_{2}\end{array}$ \\
\hline
\end{tabular}

\section{Conclusions}

The identification of selenoproteins remains one of the promising directions of modern science. This is due, as shown by the analysis of recent studies, to the active involvement of this family of proteins in the most crucial pathophysiological processes of living systems. Some mechanisms of participation of selenoproteins in the oxidative balance, redox homeostasis, carcinogenesis, neurodegeneration and myodystrophic disorders have been discovered. Methods have been developed to demonstrate the expression of certain selenoproteins in different tissues, to identify the role of these proteins in various signaling pathways.
However, many questions regarding the verification of biological functions remain open. This creates interest for specialists in many areas in further studies of selenoproteins.

\section{References}

Addinsall, A. B., Wright, C. R., Andrikopoulos, S., van der Poel, C., \& Stupka, N. (2018). Emerging roles of endoplasmic reticulum-resident selenoproteins in the regulation of cellular stress responses and the implications for metabolic disease. The Biochemical Journal, 475(6), 1037-1057.

Bang, J., Huh, J. H., Na, J. W., Lu, Q., Carlson, B. A., Tobe, R., Tsuji, P. A., Gladyshev, V. N., Hatfield, D. L., \& Lee, B. J. (2015). Cell proliferation and 
motility are inhibited by G1 phase arrest in $15-\mathrm{kDa}$ selenoprotein-deficient chang liver cells. Molecules and Cells, 38(5), 457-465.

Bang, J., Jang, M., Huh, J. H., Na, J. W., Shim, M., Carlson, B. A., Tobe, R., Tsuji, P. A., Gladyshev, V. N., Hatfield, D. L., \& Lee, B. J. (2015). Deficiency of the $15-\mathrm{kDa}$ selenoprotein led to cytoskeleton remodeling and non-apoptotic membrane blebbing through a RhoA/ROCK pathway. Biochemical and Biophysical Research Communications, 456(4), 884-890.

Bertz, M., Kühn, K., Koeberle, S. C., Müller, M. F., Hoelzer, D., Thies, K., Deubel, S., Thierbach, R., \& Kipp, A. P. (2018). Selenoprotein H controls cell cycle progression and proliferation of human colorectal cancer cells. Free Radical Biology and Medicine, pii: S0891-5849(18)30020-0.

Bobba, A., Casalino, E., Petragallo, V. A., \& Atlante, A. (2014). Thioredoxin/thioredoxin reductase system involvement in cerebellar granule cell apoptosis. Apoptosis, 19(10), 1497-1508.

Boukhzar, L., Hamieh, A., Cartier, D., Tanguy, Y., Alsharif, I., Castex, M., Arabo, A., El Hajji, S., Bonnet, J. J., Errami, M., Falluel-Morel, A., Chagraoui, A., Lihrmann, I., \& Anouar, Y. (2016). Selenoprotein T exerts an essential oxidoreductase activity that protects dopaminergic neurons in mouse models of Parkinson's disease. Antioxidants and Redox Signaling, 24(11), 557-574.

Brigelius-Flohé, R. (2015). The evolving versatility of selenium in biology. Antioxidants and Redox Signaling, 23(10), 757-760.

Burk, R. F., Hill, K. E., Motley, A. K., Winfrey, V. P., Kurokawa, S., Mitchell, S. L., \& Zhang, W. (2014). Selenoprotein P and apolipoprotein E receptor-2 interact at the blood-brain barrier and also within the brain to maintain an essential selenium pool that protects against neurodegeneration. FASEB Journal, 28(8), 3579-3588.

Chadani, H., Usui, S., Inoue, O., Kusayama, T., Takashima, S. I., Kato, T., Murai, H., Furusho, H., Nomura, A., Misu, H., Takamura, T., Kaneko, S., \& Takamura, M. (2018). Endogenous selenoprotein P, a liver-derived secretory protein, mediates myocardial ischemia/reperfusion injury in mice. International Journal of Molecular Science, 19(3), e878.

Chen, P., Wang, R. R., Ma, X. J., Liu, Q., \& Ni, J. Z. (2013). Different forms of selenoprotein $M$ differentially affect $A \beta$ aggregation and ROS generation. International Journal of Molecular Sciences, 14(3), 4385-4399.

Cox, A. G., Tsomides, A., Kim, A.J., Saunders, D., Hwang, K. L., Evason, K. J., Heidel, J., Brown, K. K., Yuan, M., Lien, E. C., Lee, B. C., Nissim, S., Dickinson, B., Chhangawala, S., Chang, C. J., Asara, J. M., Houvras, Y., Gladyshev,V. N., \& Goessling, W. (2016). Selenoprotein H is an essential regulator of redox homeostasis that cooperates with p53 in development and tumorigenesis. Proceedings of the National Academy of Science of the United States of America, 113(38), e5562-e5571.

Cui, S., Men, L., Li, Y., Zhong, Y., Yu, S., Li, F., \& Du, J. (2018). Selenoprotein S attenuates tumor necrosis factor- $\alpha$-induced dysfunction in endothelial cells. Mediators of Inflammation, 2018, 1625414.

Dai, J., Liu, H., Zhou, J., \& Huang, K. (2016). Selenoprotein R protects human lens epithelial cells against D-galactose-induced apoptosis by regulating oxidative stress and endoplasmic reticulum stress. International Journal of Molecular Sciences, 17(2), 231.

Du, X., Li, H., Wang, Z., Qiu, S., Liu, Q., \& Ni, J. (2013). Selenoprotein P and selenoprotein $\mathrm{M}$ block $\mathrm{Zn}^{2+}$-mediated $\mathrm{A} \beta 42$ aggregation and toxicity. Metallomics, 5(7), 861-870.

Du, X., Qiu, S., Wang, Z., Wang, R., Wang, C., Tian, J., \& Liu, Q. (2014). Direct interaction between selenoprotein $\mathrm{P}$ and tubulin. International Journal of Molecular Sciences, 15(6), 10199-10214.

Fan, R. F., Cao, C. Y., Chen, M. H., Shi, Q. X., \& Xu, S. W. (2018). Gga-let-7f-3p promotes apoptosis in selenium deficiency-induced skeletal muscle by targeting selenoprotein K. Metallmics, 7, 869-1030.

Gan, F., Hu, Z., Zhou, Y., \& Huang, K. (2017). Overexpression and low expression of selenoprotein $\mathrm{S}$ impact ochratoxin A-induced porcine cytotoxicity and apoptosis in vitro. Journal of Agricultural and Food Chemistry, 65(32), 6972-6981.

Gladyshev, V. N. (2014). Selenium and methionine sulfoxide reduction. Free Radical Biology and Medicine, 75(1), S8-S9.

Gladyshev, V. N., Amér, E. S., Berry, M. J., Brigelius-Flohé, R., Bruford, E. A., Burk, R. F., Carlson, B. A., Castellano, S., Chavatte, L., Conrad, M., Copeland, P. R., Diamond, A. M., Driscoll, D. M., Ferreiro, A., Flohé, L., Green, F. R., Guigó, R., Handy, D. E., Hatfield, D. L., Hesketh, J., Hoffmann, P. R., Holmgren, A., Hondal, R. J., Howard, M. T., Huang, K., Kim, H. Y., Kim, I. Y., Köhrle, J., Krol, A., Kryukov, G. V., Lee, B. J., Lee, B. C., Lei, X. G., Liu, Q., Lescure, A., Lobanov, A. V., Loscalzo, J., Maiorino, M., Mariotti, M., Sandeep, P. K., Rayman, M. P., Rozovsky, S., Salinas, G., Schmidt, E. E., Schomburg, L., Schweizer, U., Simonović, M., Sunde, R. A., Tsuji, P. A., Tweedie, S., Ursini, F., Whanger, P. D., \& Zhang, Y. (2016). Selenoprotein gene nomenclature. The Journal of Biological Chemistry, 291(46), 24036 24040.

Goo, J. S., Kim, Y. N., Choi, K. M., Hwang, I. S., Kim, J. E., Lee, Y. J., Kwak, M. H., Shim, S. B., Jee, S. W., Lim, C. J., Seong, J. K., \& Hwang, D. Y. (2013).
Proteomic analysis of kidneys from selenoprotein $\mathrm{M}$ transgenic rats in response to increased bioability of selenium. Clinical Proteomics, 10(1), 10.

Grosch, M., Fuchs, J., Bösl, M., Winterpacht, A., \& Tagariello, A. (2013). Selenoprotein $\mathrm{M}$ is expressed during bone development. EXCLI Journal, 12, 967-979.

Guariniello, S., Colonna, G., Raucci, R., Costantini, M., Di Bernardo, G., Bergantino, F., Castello, G., \& Costantini, S. (2014). Structure-function relationship and evolutionary history of the human selenoprotein M (SelM) found overexpressed in hepatocellular carcinoma. Biochimica et Biophysica Acta, 1844(2), 447-456.

Guerriero, E., Accardo, M., Capone, F., Colonna, G., Castello, G., \& Costantini, S. (2014). Assessment of the Selenoprotein M (SELM) over-expression on human hepatocellular carcinoma tissues by immunohistochemistry. European Journal of Histochemistry, 58(4), 287-290.

Hamieh, A., Cartier, D., Abid, H., Calas, A., Burel, C., Bucharles, C., Jehan, C., Grumolato, L., Landry, M., Lerouge, P., Anouar, Y., \& Lihrmann, I. (2017). Selenoprotein $\mathrm{T}$ is a novel OST subunit that regulates UPR signaling and hormone secretion. EMBO Reports, 18(11), 1935-1946.

Hernandez, A., \& Stohn, J. P. (2018). The type 3 deiodinase: Epigenetic control of brain thyroid hormone action and neurological function. International Journal of Molecular Sciences, 19(6), e1804.

Huang, J. Q., Ren, F. Z., Jiang, Y. Y., \& Lei, X. (2016). Characterization of selenoprotein $\mathrm{M}$ and its response to selenium deficiency in chicken brain. Biological Trace Element Resesrch, 170(2), 449-458.

Ishikura, K., Misu, H., Kumazaki, M., Takayama, H., Matsuzawa-Nagata, N., Tajima, N., Chikamoto, K., Lan, F., Ando, H., Ota, T., Sakurai, M., Takeshita, Y., Kato, K., Fujimura, A., Miyamoto, K., Saito, Y., Kameo, S., Okamoto, Y., Takuwa, Y., Takahashi, K., Kidoya, H., Takakura, N., Kaneko, S., \& Takamura, T. (2014). Selenoprotein P as a diabetes-associated hepatokine that impairs angiogenesis by inducing VEGF resistance in vascular endothelial cells. Diabetologia, 57(9), 1968-1976.

Kim, J. Y., Kim, Y., Kwak, G. H., Oh, S. Y., \& Kim, H. Y. (2014). Over-expression of methionine sulfoxide reductase $\mathrm{A}$ in the endoplasmic reticulum increases resistance to oxidative and ER stresses. Acta Biochimica and Biophysica Sinica, 46(5), 415-419.

Kim, K. Y., Kwak, G. H., Singh, M. P., Gladyshev, V. N., \& Kim, H. Y. (2017). Selenoprotein MsrB1 deficiency exacerbates acetaminophen-induced hepatotoxicity via increased oxidative damage. Archives of Biochemistry and Biophisics, 634, 69-75.

Kim, Y., Goo, J. S., Kim, I. Y., Kim, J. E., Kwak, M. H., Go, J., Shim, S., Hong, J. T., Hwang, D. Y., \& Seong, J. K. (2014). Identification of the responsible proteins for increased selenium bioavailability in the brain of transgenic rats overexpressing selenoprotein M. International Journal of Molecular Medicine, 34(6), 1688-1698.

Kipp, A. P., Frombach, J., Deubel, S., \& Brigelius-Flohé, R. (2013). Selenoprotein $\mathrm{W}$ as biomarker for the efficacy of selenium compounds to act as source for selenoprotein biosynthesis. Methods in Enzymology, 527, 87-112.

Kwak, G. H., \& Kim, H. Y. (2017). MsrB3 deficiency induces cancer cell apoptosis through p53-independent and ER stress-dependent pathways. Archives of Biochemistry and Biophysics, 621, 1-5.

Lee, B. C., Lee, S. G., Choo, M. K., Kim, J. H., Lee, H. M., Kim, S., Fomenko, D. E., Kim, H. Y., Park, J. M., \& Gladyshev, V. N. (2017). Selenoprotein MsrB1 promotes anti-inflammatory cytokine gene expression in macrophages and controls immune response in vivo. Scientific Reports, 7(1), 5119.

Lee, J. H., Kwon, J. H., Jeon, Y. H., Ko, K. Y., Lee, S. R., \& Kim, I. Y. (2014). Pro178 and Pro183 of selenoprotein S are essential residues for interaction with $\mathrm{p} 97(\mathrm{VCP})$ during endoplasmic reticulum-associated degradation. The Journal of Biological Chemistry, 289(20), 13758-13768.

Lee, J. H., Park, K. J., Jang, J. K., Jeon, Y. H., Ko, K. Y., Kwon, J. H., Lee, S. R., \& Kim, I. Y. (2015). Selenoprotein S-dependent selenoprotein K binding to $\mathrm{p} 97(\mathrm{VCP})$ protein is essential for endoplasmic reticulum-associated degradation. The Journal of Biological Chemistry, 290(50), 29941-29952.

Li, M., Cheng, W., Nie, T., Lai, H., Hu, X., Luo, J., Li, F., \& Li, H. (2018). Selenoprotein $\mathrm{K}$ mediates the proliferation, migration, and invasion of human choriocarcinoma cells by negatively regulating human chorionic gonadotropin expression via ERK, p38 MAPK, and akt signaling pathway. Biological trace element research, 184(1), 47-59.

Liu, J., Zhang, Z., \& Rozovsky, S. (2014). Selenoprotein K form an intermolecular diselenide bond with unusually high redox potential. FEBS Letters, 588(18), 3311-3321.

Liu, L. X., Zhou, X. Y., Li, C. S., Liu, L. Q., Huang, S. Y., \& Zhou, S. N. (2013). Selenoprotein $\mathrm{S}$ expression in the rat brain following focal cerebral ischemia. Neurological Sciences: Official Journal of the Italian Neurological Society and of the Italian Society of Clinical Neurophysiology, 34(9), 1671-1678.

Ma, Y. M., Guo, Y. Z., Ibeanu, G., Wang, L. Y., Dong, J. D., Wang, J., Jing, L., Zhang, J. Z., \& Li, P. A. (2017). Overexpression of selenoprotein H prevents mitochondrial dynamic imbalance induced by glutamate exposure. International Journal of Biological Sciences, 13(11), 1458-1469. 
Marciel, M. P., Khadka, V. S., Deng, Y., Kilicaslan, P., Pham, A., Bertino, P., Lee, K Chen, S., Glibetic, N., Hoffmann, F. W., Matter, M. L., \& Hoffmann, P. R (2018). Selenoprotein $\mathrm{K}$ deficiency inhibits melanoma by reducing calcium flux required for tumor growth and metastasis. Oncotarget, 9(17), 13407-13422.

Misu, H., Takamura, T., Takayama, H., Hayashi, H., Matsuzawa-Nagata, N., Kurita, S., Ishikura, K., Ando, H., Takeshita, Y., Ota, T., Sakurai, M., Yamashita, T., Mizukoshi, E., Yamashita, T., Honda, M., Miyamoto, K., Kubota, T., Kubota N., Kadowaki, T., Kim, H. J., Lee, I. K., Minokoshi, Y., Saito, Y., Takahashi, K. Yamada, Y., Takakura, N., \& Kaneko, S. (2010). A liver-derived secretory protein, selenoprotein P, causes insulin resistance. Cell Metabolism, 12(5), 483-495.

Misu, H., Takayama, H., Saito, Y., Mita, Y., Kikuchi, A., Ishii, K. A., Chikamoto, K. Kanamori, T., Tajima, N., Lan, F., Takeshita, Y., Honda, M., Tanaka, M., Kato, S., Matsuyama, N., Yoshioka, Y., Iwayama, K., Tokuyama, K., Akazawa, N., Maeda, S., Takekoshi, K., Matsugo, S., Noguchi, N., Kaneko, S., \& Takamura, T. (2017). Deficiency of the hepatokine selenoprotein P increases responsiveness to exercise in mice through upregulation of reactive oxygen species and AMP-activated protein kinase in muscle. Nature Medicine, 23(4), 508-516.

Mita, Y., Nakayama, K., Inari, S., Nishito, Y., Yoshioka, Y., Sakai, N., Sotani, K., Nagamura, T., Kuzuhara, Y., Inagaki, K., Iwasaki, M., Misu, H., Ikegawa, M. Takamura, T., Noguchi, N., \& Saito, Y. (2017). Selenoprotein P-neutralizing antibodies improve insulin secretion and glucose sensitivity in type 2 diabetes mouse models. Nature Communications, 8(1), 1658.

Moghadaszadeh, B., Rider, B. E., Lawlor, M. W., Childers, M. K., Grange, R. W., Gupta, K., Boukedes, S. S., Owen, C. A., \& Beggs, A. H. (2013). Selenoprotein $\mathrm{N}$ deficiency in mice is associated with abnormal lung development. FASEB Journal, 27(4), 1585-1599.

Na, J., Jung, J., Bang, J., Lu, Q., Carlson, B. A., Guo, X., Gladyshev, V. N., Kim, J., Hatfield, D. L., \& Lee, B. J. (2018). Selenophosphate synthetase 1 and its role in redox homeostasis, defense and proliferation. Free Radical Biology and Medicine, 127, 190-197.

Noh, M. R., Kim, K. Y., Han, S. J., Kim, J. I., Kim, H. Y., \& Park, K. M. (2017) Methionine sulfoxide reductase A deficiency exacerbates cisplatin-induced nephrotoxicity via increased mitochondrial damage and renal cell death. Antioxidants and Redox Signaling, 27(11), 727-741.

Pietschmann, N., Rijntjes, E., Hoeg, A., Stoedter, M., Schweizer, U., Seemann, P. \& Schomburg, L. (2014). Selenoprotein P is the essential selenium transporter for bones. Metallomics: Integrated Biometal Science, 6(5), 1043-1049.

Pitts, M. W., Byrns, C. N., Ogawa-Wong, A. N., Kremer, P., \& Berry, M. J. (2014). Selenoproteins in nervous system development and function. Biological Trace Element Research, 161(3), 231-245.

Prevost, G., Arabo, A., Jian, L., Quelennec, E., Cartier, D., Hassan, S., FalluelMorel, A., Tanguy, Y., Gargani, S., Lihrmann, I., Kerr-Conte, J., Lefebvre, H., Pattou, F., \& Anouar, Y. (2013). The PACAP-regulated gene selenoprotein T is abundantly expressed in mouse and human $\beta$-cells and its targeted inactivation impairs glucose tolerance. Endocrinology, 154(10), 3796-3806.

Qiao, X., Tian, J., Chen, P., Wang, C., Ni, J., \& Liu, Q. (2013). Galectin-1 is an interactive protein of selenoprotein $\mathrm{M}$ in the brain. International Journal of Molecular Sciences, 14(11), 22233-22245.

Rederstorff, M., Castets, P., Arbogast, S., Lainé, J., Vassilopoulos, S., Beuvin, M., Dubourg, O., Vignaud, A., Ferry, A., Krol, A., Allamand, V., Guicheney, P., Ferreiro, A., \& Lescure, A. (2011). Increased muscle stress-sensitivity induced by selenoprotein $\mathrm{N}$ inactivation in mouse: A mammalian model for SEPN1-related myopathy. PLoS One, 6(8), 1-13.

Sattar, H., Yang, J., Zhao, X., Cai, J., Liu, Q., Ishfaq, M., Yang, Z., Chen, M., Zhang, Z., \& Xu, S. (2018). Selenoprotein-U (SelU) knockdown triggers autophagy through PI3K-Akt-mTOR pathway inhibition in rooster Sertoli cells. Metallmics, 10(7), 929-940.

Short, S. P., \& Williams, C. S. (2017). Selenoproteins in tumorogenesis and cancer progression. Advances in Cancer Research, 136, 49-83.

Singh, M. P., Kim, K. Y., \& Kim, H. Y. (2017). Methionine sulfoxide reductase A deficiency exacerbates acute liver injury induced by acetaminophen. Biochemical and Biophysical Research Communications, 484(1), 189-194.

Speckmann, B., Gerloff, K., Simms, L., Oancea, I., Shi, W., McGuckin, M. A., Radford-Smith, G., Khanna, K. K., Speckmann, B., Gerloff, K., Simms, L., Oancea, I., Shi, W., McGuckin, M. A., Radford-Smith, G., \& Khanna, K. K. (2014). Selenoprotein $\mathrm{S}$ is a marker but not a regulator of endoplasmic reticulum stress in intestinal epithelial cells. Free Radical Biology and Medicine, 67, 265-277.

Tanguy, Y., Falluel-Morel, A., Arthaud, S., Boukhzar, L., Manecka, D. L., Chagraoui, A., Prevost, G., Elias, S., Dorval-Coiffec, I., Lesage, J., Vieau, D., Lihr- mann, I., Jégou, B., \& Anouar, Y. (2011). The PACAP-regulated gene selenoprotein $\mathrm{T}$ is highly induced in nervous, endocrine, and metabolic tissues during ontogenetic and regenerative processes. Endocrinology, 152(11) 4322-4335.

Tian, J., Liu, J., Li, J., Zheng, J., Chen, L., Wang, Y., Liu, Q., \& Ni, J. (2018). The interaction of selenoprotein $\mathrm{F}$ (SELENOF) with retinol dehydrogenase 11 RDH11) implied a role of SELENOF in vitamin A metabolism. Nutrition and Metabolism, 15(7), 1-9.

Tobe, R., \& Mihara, H. (2018). Delivery of selenium to selenophosphate synthetase for selenoprotein biosynthesis. Biochimica and Biophysica Acta, 1, pii: S0304-4165(18)30155-7.

Varlamova, E. G., \& Novoselov, V. I. (2012). Poisk partnjorov novogo selenovogo belka mlekopitajushhih (SELV) i jekspressiya ego $\mathrm{mRNK} v$ processe ontogeneza i spermatogeneza [The search of partners of a new mammalian selenium-containing protein $\mathrm{V}$ (SelV) and expression it's mRNA during ontogenesis and spermatogenesis]. Moleculiarnaia Biologiia, 46(2), 276-284 (in Russian).

Varlamova, E. G., Goltyaev, M. V., Novoselov, V. I., \& Fesenko, E. E. (2017). Cloning, intracellular localization, and expression of the mammalian selenocysteine-containing protein SELENOI (Sell) in tumor cell lines. Doclady Biochemistry and Biophysics, 476(1), 320-322.

Varlamova, E. G., Novoselov, S. V., \& Novoselov, V. I. (2015). Klonirovanie KDNK, jekspressiya i opredelenie substratnoj spetcifichnosti selenosoderzhashhego belka myshy SELV(SELENOPROTEIN V) [cDNA cloning, expression and determination of substrate specificity of mice selenocysteine-containing protein SelV (Selenoprotein V)]. Moleculiarnaia Biologiia, 49(5), 785-789 (in Russian)

Wang, C., Chen, P., He, X., Peng, Z., Chen, S., Zhang, R., Cheng, J., \& Liu, Q. (2017). Direct interaction between selenoprotein $R$ and A $\beta 42$. Biochemical and Biophysical Research Communications, 489(4), 509-514.

Wright, C. R., Allsopp, G. L., Addinsall, A. B., McRae, N. L., Andrikopoulos, S. \& Stupka, N. (2017). A reduction in selenoprotein S amplifies the inflamematory profile of fast-twitch skeletal muscle in the mdx dystrophic mouse. Mediators of Inflammation, 2017, 7043429.

Wrobel, J. K., Power, R., \& Toborek, M. (2016). Biological activity of selenium: Revisited. IUBMB Life, 68(2), 97-105.

Wu, R. T., Cao, L., Chen, B. P., \& Cheng, W. H. (2014). Selenoprotein H suppresses cellular senescence through genome maintenance and redox regulation. The Journal of Biological Chemistry, 289(49), 34378-34388.

Yan, J., Fei, Y., Han, Y., \& Lu, S. (2016). Selenoprotein O deficiencies suppress chondrogenic differentiation of ATDC5 cells. Cell Biology International, 40(10), 1033-1040.

Yang, S. J., Hwang, S. Y., Choi, H. Y., Yoo, H. J., Seo, J. A., Kim, S. G., Kim, N. H., Baik, S. H., Choi, D. S., \& Choi, K. M. (2011). Serum selenoprotein P levels in patients with type 2 diabetes and prediabetes: Implications for insulin resistance, inflammation, and atherosclerosis. The Journal of Clinical Endocrinology and Metabolism, 96(8), 1325-1329.

Yao, H., Fan, R., Zhao, X., Zhao, W., Liu,W., Yang, J., Sattar, H., Zhao, J. Zhang, Z., \& Xu, S. (2016). Selenoprotein W redox-regulated $\mathrm{Ca}^{2+}$ channels correlate with selenium deficiency-induced muscles $\mathrm{Ca}^{2+}$ leak. Oncotarget, 7(36), 57618-57632.

Ye, Y., Bian, W., Fu, F., Hu, J., \& Liu, H. (2018). Selenoprotein S inhibits inflammation-induced vascular smooth muscle cell calcification. Journal of Biological Inorganic Chemistry, 23(5), 739-751.

Yu, D., Zhang, Z. W., Yao, H. D., Li, S., \& Xu, S. W. (2014). Antioxidative role of selenoprotein $\mathrm{W}$ in oxidant-induced chicken splenic lymphocyte death. Biometals, 27(2), 277-291.

Yu, D., Zhang, Z., Yao, H., Li, S., \& Xu, S. W. (2015). The role of selenoprotein $\mathrm{W}$ in inflammatory injury in chicken immune tissues and cultured splenic lymphocyte. Biometals, 28(1), 75-87.

Zachara, B. A. (2015). Selenium and selenium-dependent antioxidants in chronic kidney disease. Advances in Clinical Chemistry, 68, 131-151.

Zhang, J. L., Zhang, Z. W., Shan, A. S., \& Xu, S. W. (2014). Effects of dietary selenium deficiency or excess on gene expression of selenoprotein $\mathrm{N}$ in chicken muscle tissues. Biological Trace Element Research, 157(3), 234-241.

Zhou, J., Li, C., Gu, G., Wang, Q., \& Guo, M. (2018). Selenoprotein N was required for the regulation of selenium on the uterine smooth muscle contraction in mice. Biological Trace Element Research, 183(1), 138-146.

Zoidis, E., Seremelis, I., Kontopoulos, N., \& Danezis, G. P. (2018). Selenium-dependent antioxidant enzymes: Actions and properties of selenoproteins. Antioxidants, 7(5), 66 